\title{
Wdpcp regulates cellular proliferation and differentiation in the developing limb via hedgehog signaling
}

\author{
Mark T. Langhans ${ }^{1}$, Jingtao Gao', Ying Tang ${ }^{1}$, Bing Wang ${ }^{1}$, Peter Alexander ${ }^{1}$ and Rocky S. Tuan ${ }^{1,2^{*}}$
}

\begin{abstract}
Background: Mice with a loss of function mutation in $W d p c p$ were described previously to display severe birth defects in the developing heart, neural tube, and limb buds. Further characterization of the skeletal phenotype of Wdpcp null mice was limited by perinatal lethality.

Results: We utilized Prx1-Cre mice to generate limb bud mesenchyme specific deletion of Wdpcp. These mice recapitulated the appendicular skeletal phenotype of the Wdpcp null mice including polydactyl and limb bud signaling defects. Examination of late stages of limb development demonstrated decreased size of cartilage anlagen, delayed calcification, and abnormal growth plates. Utilizing in vitro assays, we demonstrated that loss of Wdpcp in skeletal progenitors lead to loss of hedgehog signaling responsiveness and associated proliferative response. In vitro chondrogenesis assays showed this loss of hedgehog and proliferative response was associated with decreased expression of early chondrogenic marker N-Cadherin. E14.5 forelimbs demonstrated delayed ossification and expression of osteoblast markers Runx2 and Sp7. P0 growth plates demonstrated loss of hedgehog signaling markers and expansion of the hypertrophic zones of the growth plate. In vitro osteogenesis assays demonstrated decreased osteogenic differentiation of Wdpcp null mesenchymal progenitors in response to hedgehog stimulation.

Conclusions: These findings demonstrate how Wdpcp and associated regulation of the hedgehog signaling pathway plays an important role at multiple stages of skeletal development. Wdpcp is necessary for positive regulation of hedgehog signaling and associated proliferation is key to the initiation of chondrogenesis. At later stages, Wdpcp facilitates the robust hedgehog response necessary for chondrocyte hypertrophy and osteogenic differentiation.
\end{abstract}

Keywords: Hedgehog, Growth plate, Limb bud, Wdpcp, Osteogenesis, Chondrogenesis, Proliferation, Differentiation

\footnotetext{
*Correspondence: tuanr@cuhk.edu.hk

'Department of Orthopaedic Surgery, Center for Cellular and Molecular Engineering, University of Pittsburgh School of Medicine, 450 Technology

Drive, Pittsburgh, PA 15219-3143, USA

${ }^{2}$ Present Address: Institute for Tissue Engineering and Regenerative Medicine,

The Chinese University of Hong Kong, Shatin, Hong Kong SAR, China
}

(C) The Author(s). 2021 Open Access This article is licensed under a Creative Commons Attribution 4.0 International License, which permits use, sharing, adaptation, distribution and reproduction in any medium or format, as long as you give appropriate credit to the original author(s) and the source, provide a link to the Creative Commons licence, and indicate if changes were made. The images or other third party material in this article are included in the article's Creative Commons licence, unless indicated otherwise in a credit line to the material. If material is not included in the article's Creative Commons licence and your intended use is not permitted by statutory regulation or exceeds the permitted use, you will need to obtain permission directly from the copyright holder. To view a copy of this licence, visit http://creativecommons.org/licenses/by/4.0/. The Creative Commons Public Domain Dedication waiver (http://creativecommons.org/publicdomain/zero/1.0/) applies to the data made available in this article, unless otherwise stated in a credit line to the data. 


\section{Background}

The primary cilium is a transiently formed microtubulebased organelle that coordinates many signaling processes within vertebrate development and has been found in almost all vertebrate cell types [1]. There are several hundred proteins and associated complexes controlling formation and maintenance of the cilium [2]. Mutations in the genes encoding these proteins are associated with diseases known as ciliopathies with a wide array of associated phenotypes affecting almost all organ systems [3].

One the key complexes necessary for initiation of ciliogenesis is the CPLANE complex, whose members include Wdpcp, Intu, and Fuz [4]. The CPLANE complex has been shown to regulate intraflagellar transport proteins (IFT) necessary for formation of the primary cilium [5]. Several studies of the IFT proteins have demonstrated important roles for these proteins in the limb bud, growth plate [6,7], chondrocyte differentiation $[8,9]$, osteoblast differentiation [10-12], and homeostasis of adult skeletal tissues [9, 13-16]. Although the role of CPLANE proteins in skeletal development has been less intensively studied, $W d p c p^{-/-}$ [17], $\mathrm{Fuz}^{-/-}$[18], and $\mathrm{Intu}^{-/-}[19,20]$ mice have been characterized. While examination of later stages in skeletal development of these mutants has been limited by lethality, analysis of the limb buds demonstrates polydactyly and altered hedgehog signaling.

An unbiased $N$-ethyl- $N$-nitrosurea (ENU) induced mutagenesis screen in mice for homozygous recessive mutations recovered the Cys40 mouse bearing a null mutation in Wdpcp [17]. Wdpcp was first identified in Drosophila melanogaster as Fritz [21], and the vertebrate homolog was later demonstrated to play a role in hedgehog signaling and ciliogenesis [17, 22]. Mutations in WDPCP in humans are associated with Bardet-Biedl Syndrome and Meckel Gruber Syndrome, ciliopathy disorders with features that include polydactyly, congenital heart defects, renal abnormalities, blindness, truncal obesity, and genitourinary malformations [23].

The Cys40 mice had disrupted ciliogenesis and displayed a gross appendicular skeletal phenotype of polydactyly and shortened, dysmorphic long bones. Analysis of the limb buds showed disrupted formation of truncated Gli3 repressor and altered hedgehog signaling. In addition to the skeletal phenotype, the Cys40 mutant had a number of developmental defects including congenital heart malformations, cystic kidneys, tracheoesophageal fistula, and cloacal septation defects that lead to embryonic lethality. A conditional deletion mouse model of Wdpcp bearing LoxP sites on either side of exon 5 was confirmed to recapitulate the phenotype of the Cys40 mutant when crossed with a constitutively expressed CMV-Cre [17].
We generated Prx1-Cre; Wdpcp ${ }^{\text {Flox/Cys } 40}$ mice to bypass the high perinatal lethality of the $W d p c p$ constituitive knockout mice and facilitate study of the role of Wdpcp in later stages of skeletal development including the organization of the growth plate and ossification of appendicular skeletal elements. Histomorphometric characterization of the developing limbs demonstrated diminished size of the skeletal elements and delayed ossification. These findings corresponded with delayed expression of chondrocyte hypertrophy/early osteoblast markers. Consistent with prior studies of genes necessary for ciliogenesis $[6,12,13,24-26]$, we noted alteration of hedgehog pathway activation in the developing limb bud as well as the growth plate. These findings were explored further with in vitro assays that demonstrated decreased proliferation, and delayed early chondrogenic and osteogenic differentiation of mesenchymal progenitor cells lacking Wdpcp in response to hedgehog stimulation. In summary, we demonstrate a critical role for Wdpcp in modulating hedgehog signaling to facilitate multiple processes in mammalian appendicular skeletal development including proliferation, growth plate organization, and differentiation of skeletal precursors.

\section{Results}

Wdpcp is expressed in skeletal tissues, and limb mesenchyme specific deletion of Wdpcp recapitulates the Cys40 appendicular skeleton phenotype

Quantification of RNA transcripts of $W d p c p$ in multiple tissues confirmed that $W d p c p$ is widely expressed and is enriched in musculoskeletal tissues (Fig. 1A). We chose to focus our studies specifically on the appendicular skeleton and wanted to determine the spatiotemporal requirement for $W d p c p$ for normal appendicular skeletogenesis. Previous conditional gene knockout studies in mice had demonstrated proteins necessary for normal primary cilia formation functioned within the limb bud mesenchyme to facilitate skeletogenesis [12]. Based on these studies, we hypothesized that $W d p c p$ deletion from the limb bud mesenchyme would recapitulate the Cys 40 phenotype. We utilized a conditional allele of Wdpcp in combination with the Prx1-Cre mouse to confirm that $W d p c p$ functions within the limb bud mesenchyme. The Prx1-Cre mouse expresses Cre recombinase in the forelimb bud mesenchyme at E9.5 and in the hindlimb bud mesenchyme at E10.5 [27]. Mice with a limb bud mesenchyme specific deletion of Wdpcp were generated by crossing the Prx 1-Cre;Wdpcp Cys40/+ mice to the $W d p c p^{\text {Flox/Flox }}$ mice. Quantification of RNA transcripts as well as Western Blot for Wdpcp protein confirmed deletion of Wdpcp in E11.5 limb buds (Fig. 1B,C). Alizarin Red/Alcian Blue staining of E17.5 Prx1-Cre; Wdpcp ${ }^{\text {Flox/+ }}$ mice (control) (Fig. 1D) and Prx1-Cre; $W d p c p^{F l o x / C y s 40}$ (Wdpcp-cKO) mice (Fig. 1E) revealed a 


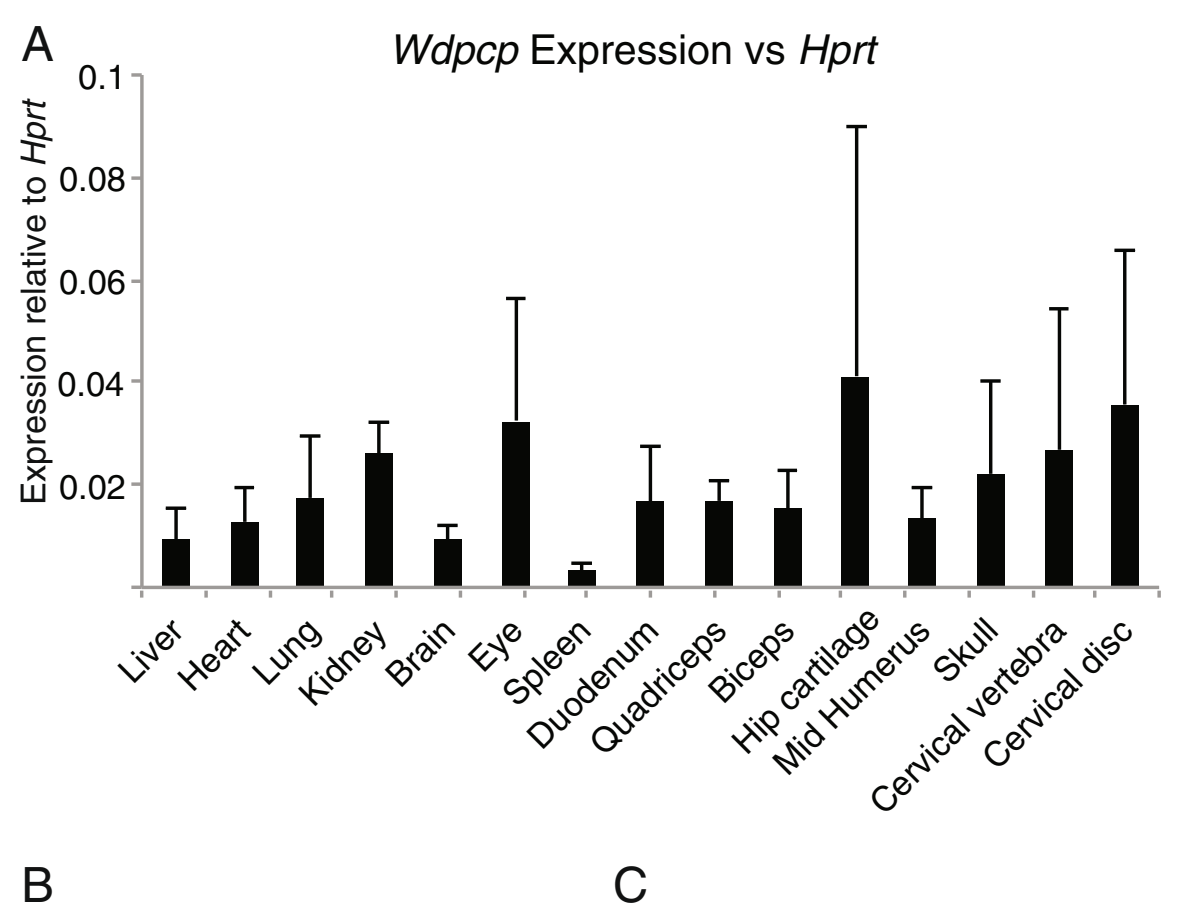

Wdpcp E11.5 Limb Bud Expression

Wdpcp E11.5 Limb Bud Expression
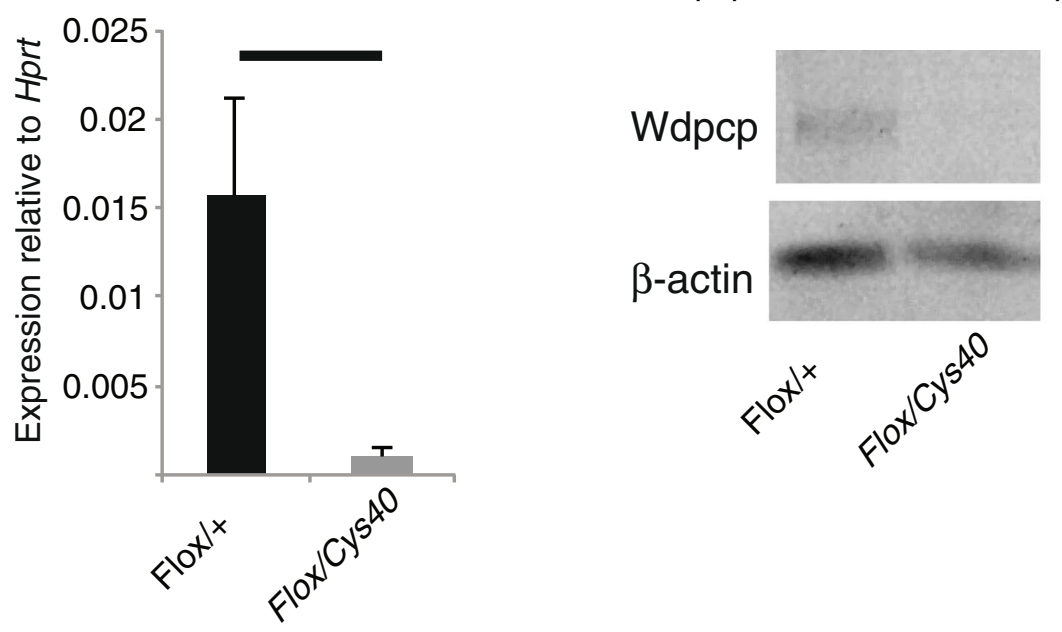

D Prx1Cre;Wdpcp ${ }^{\text {Floxt+ }}$

E Prx1Cre;Wdpcp ${ }^{\text {FloxCys40 }}$
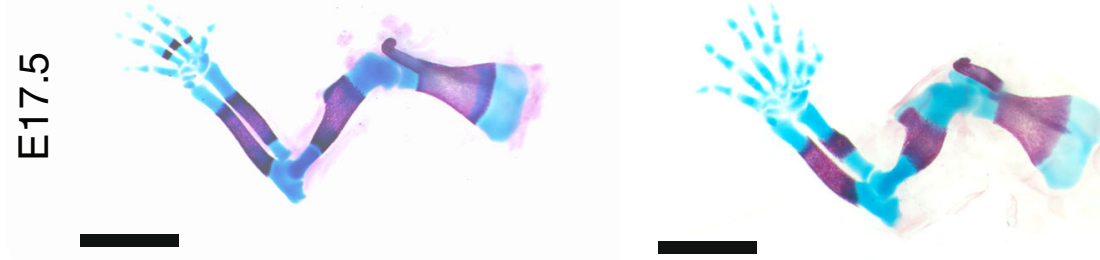

Fig. 1 (See legend on next page.) 
(See figure on previous page.)

Fig. $1 \mathrm{Wdpcp}$ is highly expressed in musculoskeletal tissues and loss of expression in limb bud mesenchyme is associated with ossification, patterning, and growth defects. A RT-PCR analysis of Wdpcp expression in several adult tissues. B Expression of Wdpcp RNA transcripts and (C) Wdpcp protein expression in E11.5 limb buds from Prx1-Cre;Wdpcp ${ }^{\text {Flox }++}$ (control) and Prx1-Cre;Wdpcp Flox/Cys40 (Wdpcp-cKO) mice. D, E E17.5 forelimbs stained with Alizarin Red and Alcian Blue showing areas of ossification (red) and cartilaginous condensation (blue) as well as gross skeletal phenotype of Prx1-Cre;Wdpcp ${ }^{\text {Flox }++}$ (control) and Prx1-Cre;Wdpcp ${ }^{\text {Flox/Cys40 }}$ (Wdpcp-cKO) mice. Black scale bars represent $2 \mathrm{~mm}$ in all panels

similar phenotype to that observed in the Cys 40 mutant including severe polydactyly with shortened, dysmorphic long bones [17].

\section{Prx1-Cre;Wdpcp ${ }^{\mathrm{Flox} / \mathrm{Cys} 40}$ mice have smaller cartilage anlagen, delayed ossification associated with delayed expression of chondrocyte hypertrophic marker, and expanded zone of hypertrophy in growth plates}

Histomorphometric characterization of E14.5 fore limb buds was notable for significantly decreased size of cartilage anlagen in Prx 1-Cre; Wdpcp $p^{\text {Flox } / C y s 40}$ (referred to as Wdpcp-cKO) mice versus Prx1-Cre; $W d p c p^{\text {Flox } /+}$ (referred to as control) mice. There was a trend toward progressive shortening with more distal elements (Fig. 2A-C). Additionally, it was noted that at E14.5 there was delayed ossification in the Wdpcp-cKO mice as indicated by lack of Alizarin Red staining (Fig. 2A-B). To explore this finding further, we performed immunohistochemical staining for early chondrocyte hypertrophy markers Runx2 (Cbfa1) and Sp7 (Osterix) expression of which immediately precedes calcification and vascular invasion [28]. While the controls demonstrated expected staining at the humerus primary center of ossification, there was no significant staining in the WdpcpcKO humerus (Fig. 2D, E). The P0 growth plates of the Wdpcp-cKO mice demonstrated an expanded zone of hypertrophic chondrocytes with loss of the clear zonal demarcation of the prehypertrophic and hypertrophic zones (Fig. 2F-H).

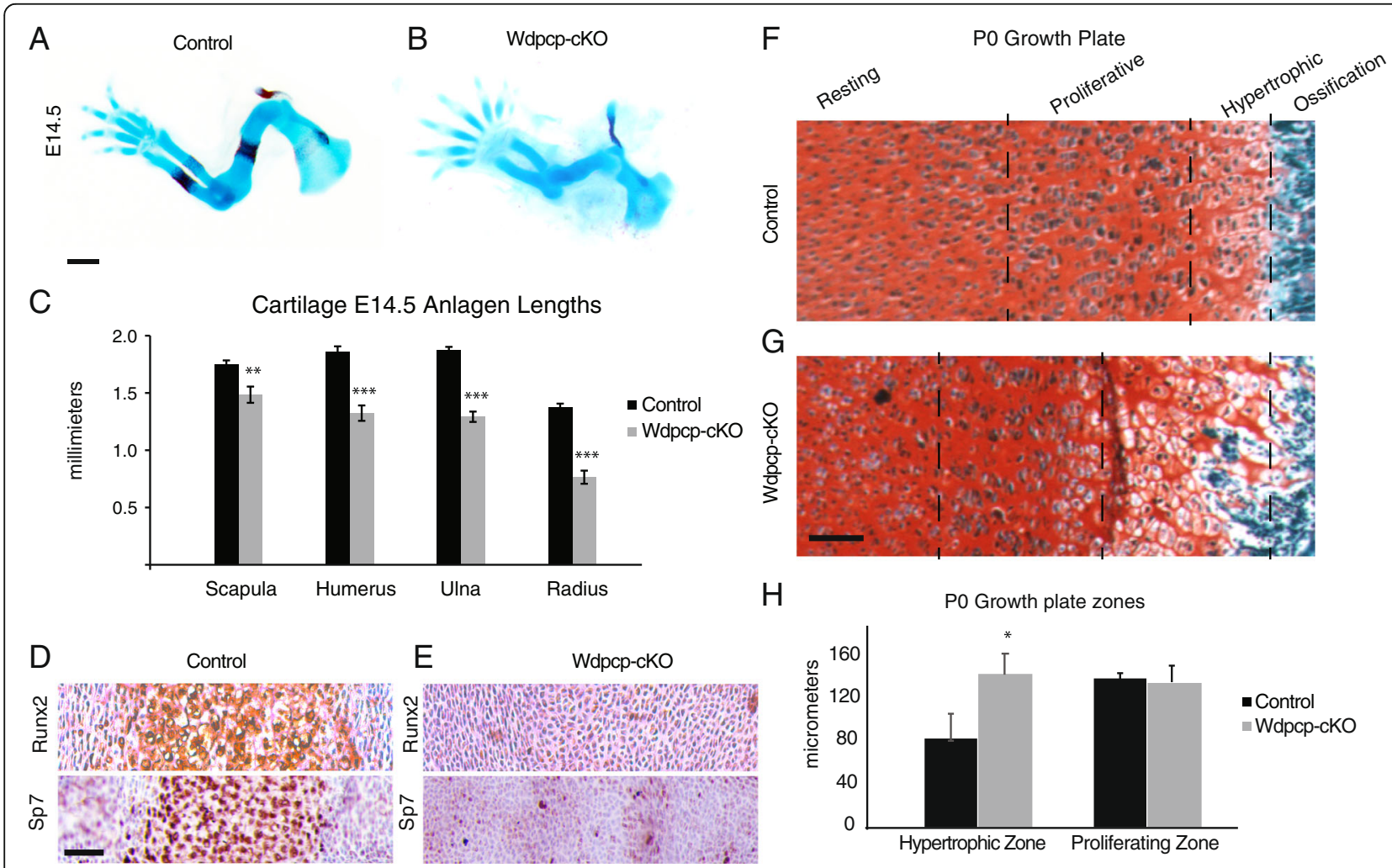

Fig. 2 Developing limbs of Wdpcp-cKO embryos have smaller appendicular skeletal cartilage anlagen, delayed expression of hypertrophic chondrocyte markers and expanded hypertrophic zones in growth plate. A-C Alcian Blue and Alizarin Red staining of E14.5 embryos with quantification of anlagen lengths. D, E Immunohistochemistry staining of E14.5 humerus for chondrocyte hypertrophy markers Runx2 and Sp7. F, G Safranin O Fast Green staining of P0 growth plates and (H) quantification of growth plate zone sizes. Scale bars are $1 \mathrm{~mm}$ for $(\mathbf{A}, \mathbf{B})$, and $50 \mu \mathrm{m}$ for (D-G). Error bars represent one standard deviation. Wdpcp-cKO is compared to matched control with * for $p<0.05,{ }^{* *}$ for $p<0.01$, and *** for $p<0.001$ 
Hedgehog signaling is disrupted at multiple stages of skeletal development in Wdpcp-cKO mice

Given that prior studies of Wdpcp reported hedgehog signaling dysfunction in the limb bud [17] and the central role this pathway plays in several aspects of skeletal development including chondrogenesis, osteogenesis, and growth plate patterning [29], we chose to investigate the effects of Wdpcp-cKO on hedgehog signaling. We utilized Gli1 expression, shown by the LacZ reporter, as marker of hedgehog pathway activity [30].

Gli1-LacZ;Prx1-Cre;Wdpcp ${ }^{\text {Flox/Cys } 40}$ (Wdpcp-cKO) E11.5 limb buds demonstrated significantly diminished staining versus control consistent with lack of full activation of the hedgehog pathway (Fig. 3A, B). Similarly,

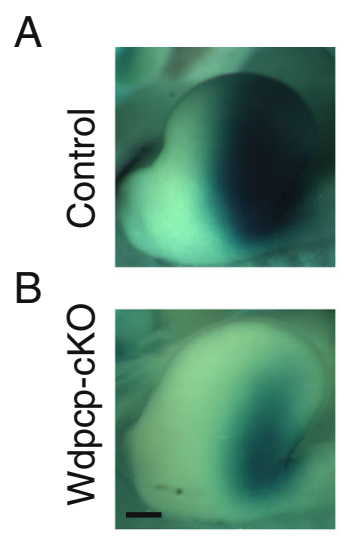

E

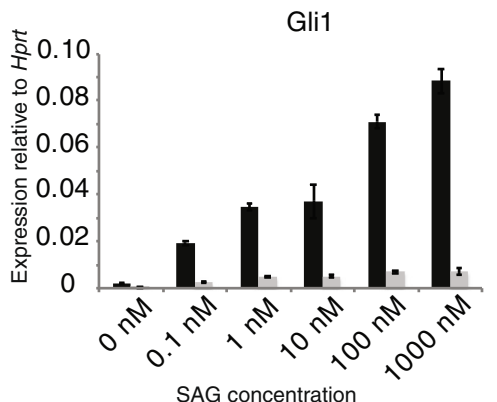

$\mathrm{H}$

C

D
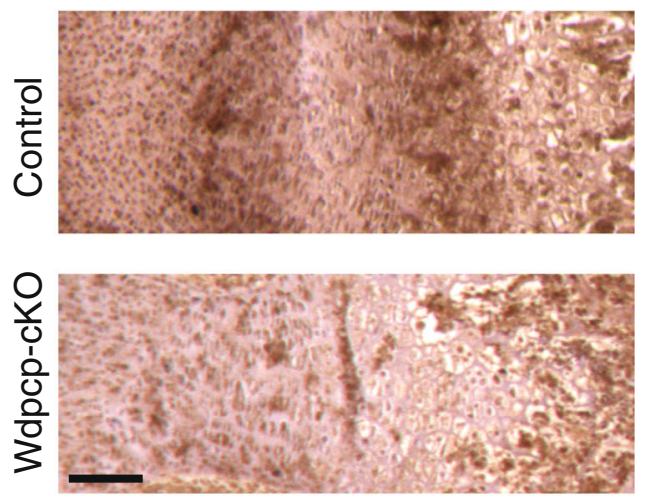

$\mathrm{F}$

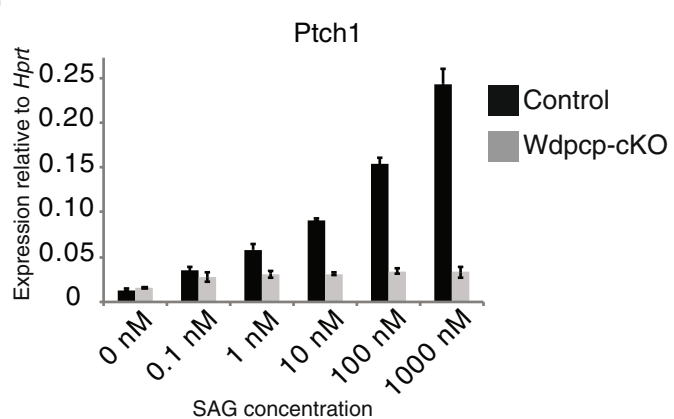

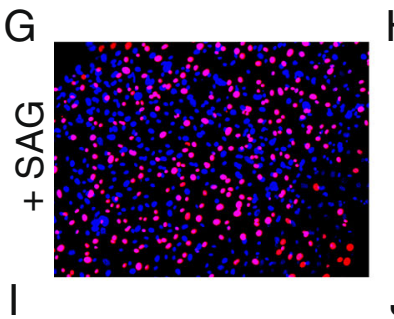

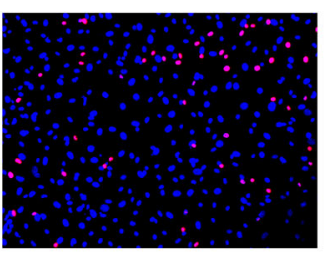

$\mathrm{J}$

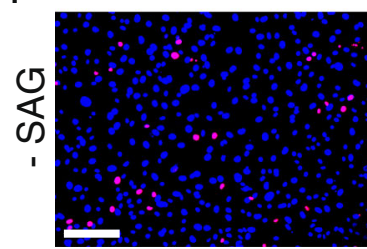

Control

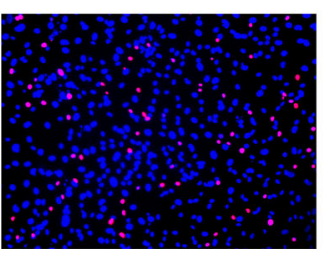

Wdpcp-cKO

Fig. 3 Wdpcp-cKO embryos have disrupted hedgehog signaling in developing limb bud and growth plate, and Wdpcp-cKO mesenchymal progenitors show diminished response to hedgehog stimulation. A, B Gli1-Lacz reporter mice were used to observe hedgehog signaling activity (blue) in Wdpcp-cKO versus control E11.5 limb buds. C, D Immunohistochemistry of P0 growth plates for hedgehog signaling reporter Gli1 in Wdpcp-cKO versus control. E, F Expression of hedgehog reporter genes Gli1 and Ptch1 in mesenchymal progenitor cells from Wdpcp-cKO embryos with increasing dosage of smoothened agonist (SAG). Error bars represent one standard deviation. G-J EdU staining for proliferative cells (red) in mesenchymal progenitor cells from Wdpcp-cKO and control with and without SAG treatment. Scale bars represent $200 \mu \mathrm{m}$ in (A, B) and $50 \mu \mathrm{m}$ in (C, D); white scale bar represents $50 \mu \mathrm{m}$ in G-J 
while Gli1 expression in P0 growth plate is typically enriched in the prehypertrophic and early proliferating chondrocytes (Fig. 3C), the Wdpcp-cKO growth plates demonstrated a distinct lack of staining or patterning (Fig. 3D). Previously published data showed failure of Gli3 repressor processing in the E10.5 limb bud [17]. This would theoretically lead to a lack of Gli3 repressor and abnormal activation of hedgehog pathway in contrast to what we observed at E11.5. The discordance of these results highlights the importance of the Wdpcp in not only repression, but also full activation of the hedgehog pathway. The importance of finely tuned hedgehog pathway sensitivity to limb development has been highlighted by recent studies [31]. Our findings suggest that in the developing limb Wdpcp is necessary not only for full repression of hedgehog signaling but also for full activation. To investigate this further, we examined the responsiveness of limb mesenchymal progenitor cells to Smo stimulation with SAG treatment, and saw a significantly diminished responsiveness in the Wdpcp-cKO cells in expression of the two hedgehog pathway responsive genes Gli1 and Ptch1 [32] (Fig. 3E, F) that correlated with decreased cilia formation (supplementary Fig. 2). Several reports have suggested that one of the primary functions of hedgehog signaling in mesenchymal progenitors is control of proliferation necessary to achieve cell density required for differentiation of skeletal tissue [33$35]$. We examined proliferation of mesenchymal progenitors in response to Smo agonist (SAG) and saw a dramatic response in control cells (Fig. 3G, I) versus a lack of proliferative response in Wdpcp-cKO cells (Fig. $3 \mathrm{H}, \mathrm{J})$. These results are in line with the histologically observable loss of clear demarcation of the proliferative zone in Wdpcp-cKO growth plates as well as the smaller anlagen size.

\section{Loss of Wdpcp disrupts early chondrogenesis}

We examined the effect of Wdpcp-cKO on mesenchymal chondrogenic differentiation using high density micromass cultures of limb bud mesenchyme and treatment with SAG. We noted similar Alcian Blue staining between Wdpcp-cKO and control (Fig. 4A-B). Similar to results with mesenchymal progenitor cells, we observed higher expression of hedgehog reporter genes Gli1 and Ptch1 (Fig. 4C, D). Prior studies have shown that Ccnd1 expression is closely correlated with proliferation in mesenchymal progenitors [36]. We found that increased expression of Gli1 and Ptch1 corresponded with increased expression of the proliferation marker Ccnd1 (Fig. 4D). Sdc3 (Sydecan 3) (Fig. 4F) and Cdh2 (N-Cadherin) are two markers of early chondrogenesis [37], and $C d h 2$ upregulation is a robust marker of early chondrogenic differentiation [38]. We noted significantly decreased expression of $\mathrm{Cdh} 2$ in Wdpcp-cKO versus control, suggesting reduced pre-chondrogenic cellular condensation (Fig. 4E). Early chondrogenic differentiation marker $S d c 3$ as well as later chondrogenic differentiation markers Sox9 and Col2a1 (Fig. 4E) had lower expression in the Wdpcp-cKO versus control, but did not reach significance.

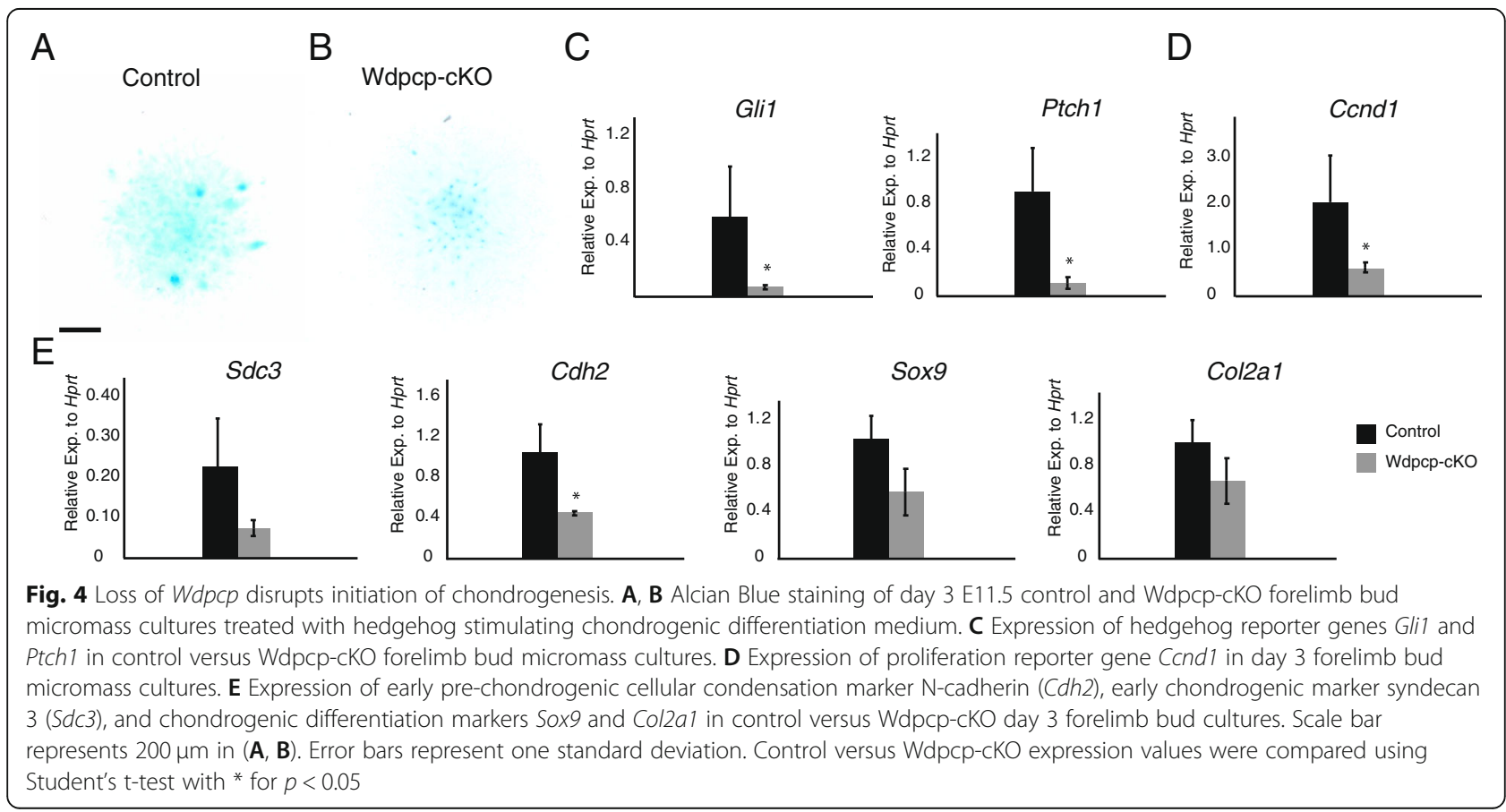


Mesenchymal progenitor cells lacking Wdpcp have impaired hedgehog mediated osteogenic differentiation Given the observation of delayed calcification (Fig. 2A, B) and expression of chondrocyte hypertrophy markers at the primary center of ossification (Fig. 2C, D), we wanted to investigate the effect of loss of Wdpcp in mesenchymal progenitor differentiation into osteoblasts. Mesenchymal progenitor cells were maintained in monolayer culture in osteogenic medium and treated with SAG. Alizarin Red S staining at 20 days of culture showed a dramatic reduction of mineralization in Wdpcp-cKO cells compared to control (Fig. 5A, B). Alkaline phosphatase activity at 4 days of culture showed significantly decreased activity in Wdpcp-cKO cells (Fig. 5C). Expression of hedgehog activity reporter genes Gli1 and Ptch 1 at 20 days of culture was significantly decreased in Wdpcp-cKO (Fig. 5D). We quantified the expression of several markers of chondrocyte hypertrophy/ osteoblast differentiation. Runx2 is one of the key chondrocyte hypertrophy markers [39]. Expression of Runx2 is necessary for expression of the key osteoblast transcription factor Osx (Sp7) [40]. Ocn and Col1a1 are key components of osteoid matrix and characteristic markers of mature osteoblasts [28]. Expression of Runx2 was not significantly different from control in Wdpcp-cKO (Fig. 5E). On the other hand, expression of Sp7, Colla1, and Ocn (Bglap2) is significantly decreased in WdpcpcKO versus control (Fig. 5E). The lack of a significant difference in $R u n x 2$ expression is likely due to its activity as an early transcriptional regulator of osteogenic differentiation, i.e., at an earlier time point than was measured in the osteogenesis assay relative to the expression of Osx (Sp7), which depends on prior upregulation of Runx2.

\section{Discussion}

The skeletal phenotype of the Wdpcp-cKO mice is similar to that of several other mutants with deficient ciliogenesis. Although mutations in proteins necessary for normal ciliogenesis typically result in perinatal lethality, some mouse models survive to later stages of development. A hypomorphic allele of the intraflagellar transport protein Ift88, the $\mathrm{Tg} 737^{\text {orpk }}$ mouse, has shortened long bones and abnormal growth plate morphology with delayed expression of chondrocyte hypertrophy marker Col10a1 [7]. Similarly, a hypomorphic allele of Intu demonstrates shortened long bones, delayed ossification, and delayed expression of hypertrophic markers with decreased hedgehog activation [20]. Mice with a hypomorphic mutation in Pocla, which encodes a centriolar protein necessary for ciliogenesis, also display shortened long bones and disorganized growth plates [41]. Mice

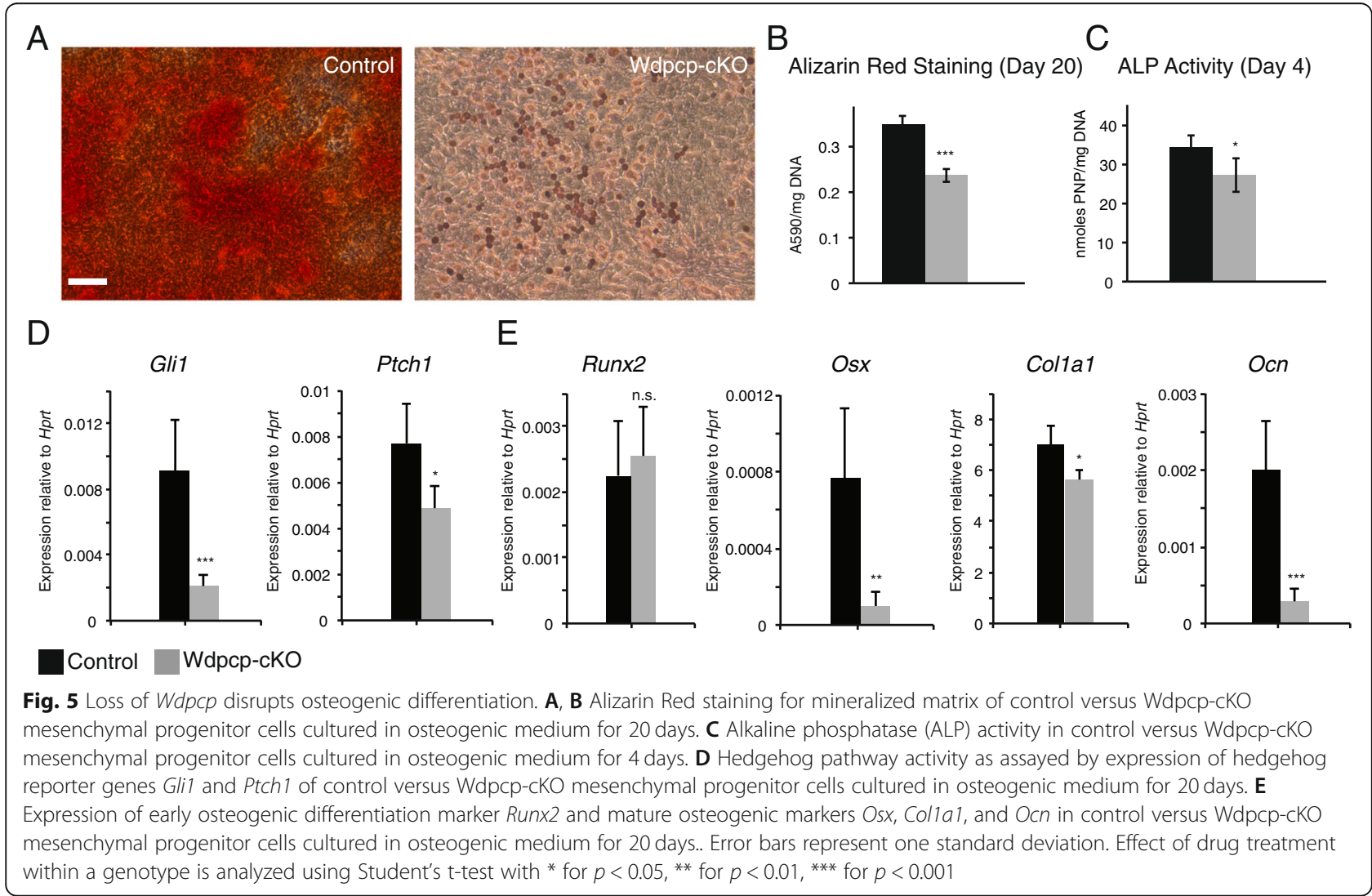


with an inactivating point mutation in Ick demonstrate shortened long bones and polydactyly with delayed hypertrophy and loss of hedgehog activation in the growth plate [42]. Talpid $3^{-/-}$mice survive to birth and have disrupted ciliogenesis and hedgehog signaling [43] with associated polydactyly, shortened long bones, and delayed chondrocyte hypertrophy with expanded zone of hypertrophy in the growth plate [44]. $E v c^{-/-}$and $E v c 2^{-/-}$ mice survive to birth and display no polydactyly, but do have shortened long bones. Evc localizes to the basal body of the chondrocyte primary cilium, and $E v c^{-1-}$ mice display disorganized growth plate structure with decreased Gli1 and Ptch1 expression [26]. Unlike the $W d p c p^{C y s 40 / C y s 40}$ mutant [17], $E v c^{-/-}$fibroblasts do not have a dramatic impairment in Gli3 full length to repressor processing, but do have decreased Gli1 expression in response to SAG [45]. Common to all of these models is a failure to activate hedgehog signaling and shortened appendicular skeletal elements.

The Wdpcp-cKO skeletal phenotype also has similarities with conditional knockout models of cilia related proteins. Prx1-Cre mice with conditional limb bud mesenchyme deletion of intraflagellar transport proteins [12, 46], kinesins [47], or basal body proteins [25] display polydactyly and shortened long bones with delayed ossification that correlates with disrupted cilia formation and loss of Gli1 expression and hedgehog signaling abnormalities similar to the Wdpcp-cKO mouse. The Wdpcp-cKO mouse represents the first conditional limb bud mesenchyme knockout of a CPLANE protein. Col2a-Cre mice with conditional deletion of Kif3a or Ift 88 at a later time point in skeletal development after chondrogenesis do not have polydactyly and have mildly shortened long bones, but do have abnormal growth plates with decreased growth plate proliferation and decreased hedgehog activation similar to the WdpcpcKO mice [6]. These studies suggest that proliferation and growth prior to onset of Col2a1 expression is an important contributor to the skeletal phenotype of the Wdpcp-cKO mice and other cilia deficient mice.

Mesenchymal proliferation and cellular condensation is essential for initiation of chondrogenesis to achieve the cell density required [34]. Additionally, tight regulation of hedgehog signaling is also critical for early initiation of chondrogenesis [29]. Recent studies of limb bud development have implicated hedgehog signaling as a key regulator of both mesenchymal limb bud progenitor proliferation and transition to chondrogenesis [36], and have highlighted the sensitivity of this process to small perturbations in the level of cilia associated hedgehog signaling activation [31]. Our findings of disrupted hedgehog signaling, decreased proliferative response, and decreased expression of early cellular condensation and chondrogenic markers in the Wdpcp-cKO mesenchymal progenitor cells is in line with these prior findings. Furthermore, they suggest that a significant contributing driver of the phenotype observed in the Wdpcp-cKO mice is related to perturbed hedgehog signaling in the later stages of limb bud mesenchyme proliferation and differentiation to early stages of chondrogenesis.

Hedgehog signaling represents the molecular pathogenic link between ciliary dysfunction and skeletal phenotype $[48,49]$. Cilia coordinate the processing of the Gli transcription factors to their shortened repressor forms [31] as well as their fully activated forms downstream of hedgehog [50]. Similar to the Wdpcp$\mathrm{cKO}$ mice, $\mathrm{Ihh}^{-1-}$ mice have shortened long bones, and knockdown of Ihh induces inhibition of cell proliferation and mature chondrocyte markers [51]. Prrx1-CreERT deletion of Ptch1 in postnatal mice activates hedgehog signaling and promotes mesenchymal progenitor proliferation as well as differentiation into chondrocytes and osteoblasts [52]. Conversely, failure to activate hedgehog signaling in Wdpcp-cKO mesenchymal progenitors slows proliferation and differentiation into chondrocyte and osteoblast. Similarly, knockdown of Ift80 and Ift88 in cultured mesenchymal progenitors disrupts ciliogenesis and has been shown to decrease chondrocyte and osteoblast differentiation [8-10, 53].

Previous studies of Wdpcp null mice have demonstrated perturbed Wnt signaling in developing heart and PCP defects including disrupted cochlear hair cell alignment with loss of Vangl2 expression as well as abnormal cell migration and cytoskeleton organization [17]. In the developing limb however, the Wdpcp-cKO mouse does not display a loss of flattening or columnar organization observed in other mutants of the PCP pathway [54-56]. Thus, while PCP may contribute in part to the observed skeletal phenotype of the Wdpcp-cKO mouse, the overlap in hedgehog signaling changes and phenotype with other cilia mutants suggests that these are significant components of the pathology. Additionally, prior studies have demonstrated that while Wnt signaling is perturbed in cilia deficient mutants, this is a downstream effect of the alteration of hedgehog signaling [57]. Interestingly, mice bearing a hypomorphic allele of the Wnt PCP receptor Prickle1 have been found to have defective ciliogenesis [58, 59], underscoring the close interplay between cilia and PCP signaling. Future studies with the Wdpcp-cKO mouse will help to elucidate the specific roles of cilia and PCP in the developing limb and to refine our molecular model of limb development and growth plate organization. 


\section{Conclusions}

The generation of the Wdpcp-cKO mouse characterized in this study established the CPLANE protein Wdpcp as essential for mouse appendicular skeletal development in both the limb bud as well later stages of skeletal development including growth plate organization. We demonstrate that there is a significant impairment in the activation of hedgehog signaling that is associated with compromised proliferation and differentiation of skeletal tissues.

\section{Methods}

\section{Mouse strains}

The $W d p c p^{C y s 40 / C y s 40}$ mouse and $W d p c p^{\text {Flox/Flox }}$ mouse have been previously described [17]. The Prx1-Cre mouse strain (Jackson Stock \#005584) and Gli1-Lacz mouse strain (Jackson Stock \#008211) were obtained from Jackson Laboratories. To avoid recombination in the female germline, male $\operatorname{Prx} 1-\mathrm{Cre} ; \mathrm{Wdpcp} \mathrm{Cys}^{\mathrm{C} 40 /+}$ mice were crossed with the female $W d p c p^{\text {Flox/Flox }}$ mice to induce limb bud mesenchyme specific deletion of the $W d p c p^{F l o x}$ allele [27], resulting in litters with Prx1-cre; $W d p c p^{\text {Flox/+ }}$ (control) and Prx1-cre;Wdpcp ${ }^{\text {Flox/Cys4O }}$ (Wdpcp-cKO) mice. Male Gli1-Lacz;Prx1-cre; $W d p c p^{C y s 40 /+}$ and female $W d p c p^{\text {Flox/Flox }}$ mice were crossed for limb bud assay. Plug date was identified as E0.5 for timed matings. All reported mice are from mixed background strains. Mutant mice were obtained in the expected Mendelian ratio for each mating, and no association of phenotype was noted with sex. All histological specimens are shown in comparison to littermates and representative of at least 3 biological samples. Mice were under care of a veterinarian, and all mice used in this study were euthanized with carbon dioxide in a $10 \mathrm{~L}$ volume chamber with a flow rate of carbon dioxide at $5 \mathrm{~L} / \mathrm{min}$ with flow maintained for 2 min following cessation of respiration followed by cervical dislocation in accordance with National Institutes of Health Office of Animal Care and Use guidelines. The study was carried out in compliance with ARRIVE guidelines.

\section{Genotyping}

For genotyping, DNA was extracted from livers of embryos and tail clips of newly weaned mice using the REDExtract-N-Amp Tissue PCR Kit (Sigma). Primers used for genotyping are included in Table 1. The $W d p c p^{\text {Cysto }}$ allele was genotyped using Sanger sequencing of a 150 base pair fragment to identify the relevant $\mathrm{A}>\mathrm{G}$ base pair change (Supplemental Fig. 1A). The $W d p c p^{F l o x}$ allele was genotyped using polymerase chain reaction (PCR) with primers to amplify a region containing an inserted flox site (424 base pair fragment) or lacking an inserted flox site (262 base pair fragment) that
Table 1 Genotyping primers

\begin{tabular}{|c|c|c|}
\hline Primer Name & Target Allele & Sequence $\left(5^{\prime}-3^{\prime \prime}\right)$ \\
\hline Cys40-F & $W d p c p^{C y 540}$ & CATGTITATTTGCCAGCACGAG \\
\hline Cys40-R & $W d p c p^{C y s 40}$ & GCGAGAGCCAGTCCTCTATG \\
\hline Flox-F & $W d p c p^{\text {Flox }}$ & GGTTTCAAAAATGGGAGCAA \\
\hline Flox-R & $W d p c p^{F l o x}$ & CTGCTTTGCATCAGTTCCTG \\
\hline Cre-F & Prx1-Cre & ACTTGGCAGCTGTCTCCAAG \\
\hline Cre-R & Prx1-Cre & GCGAACATCTTCAGGTTCTG \\
\hline
\end{tabular}

could be differentiated with agarose gel electrophoresis [17]. Presence of the Prx1-Cre allele was identified by PCR with primers specific to Cre that amplified a 102 base pair fragment (Supplemental Fig. 1B,C) [60].

\section{Skeletal preparations}

Skeletal preparations were made by co-staining embryos with Alizarin Red S for ossified, calcium rich tissue and Alcian Blue for cartilage as described previously [61]. Briefly, embryos were scalded in hot tap water, skinned, and their abdominal and thoracic organs removed. Livers were saved for genotyping. Embryos were transferred into ethanol before staining $24 \mathrm{~h}$ with $40 \%$ glacial acetic acid, $60 \%$ ethanol, 0.0001\% Alcian Blue (Sigma) solution at room temperature. Embryos were destained for $24 \mathrm{~h}$ in ethanol before being transferred to a solution containing $2 \% \mathrm{KOH}$ (Sigma) in distilled water with 0.0015\% Alizarin Red S (Sigma) for 5 h. Embryos were subsequently destained in $2 \% \mathrm{KOH}$ in distilled water overnight, followed by $1 \% \mathrm{KOH}$ in $50 \%$ glycerol $/ 50 \%$ distilled water. Embryos were transferred to 50\% glycerol/ $50 \%$ distilled water for imaging. All images are representative of at least 3 specimens. For limb length quantification, the longest vector along each cartilage element was used. Six limbs from six separate animals were used for both mutants and controls.

\section{Quantitative real time RT-PCR (qRT-PCR)}

Total RNA was extracted using TRIzol (Invitrogen) with RNeasy columns (Qiagen) for purification and removal of genomic DNA. RNA was quantified on nanodrop, and cDNA was synthesized from $200 \mathrm{ng}$ of total RNA using Superscript III (Invitrogen) with the Oligo (dT) primers per the manufacturer's protocol. Quantitative real-time PCR was performed on Applied BioSystems StepOnePlus with Applied Biosystems SYBR Green PCR mastermix in 96-well plates. Primers were all used at a concentration of $200 \mathrm{nM}$. Cycling variables were as follows: $95^{\circ} \mathrm{C}$ for 10 min, then 40 cycles of $15 \mathrm{~s}$ denaturation at $95^{\circ} \mathrm{C}$ and 1 min at $60^{\circ} \mathrm{C}$. Primer sequences are included in Table 2 . Expression was reported normalized to housekeeping gene HPRT due to reported stability of expression of this gene during skeletal development $[62,63]$. The mean and standard deviation represent 3-4 biological replicates each 
Table 2 qRT-PCR primers

\begin{tabular}{|c|c|c|c|c|}
\hline Gene & $\mathbf{P}$ & Reference & Sequence $\left(5^{\prime}-3^{\prime}\right)$ & Accession No. \\
\hline Hprt & $5^{\prime}$ & MGH PrimerBank & TCAGTCAACGGGGGACATAAA & NM_013556 \\
\hline Hprt & $3^{\prime}$ & MGH PrimerBank & GGGGCTGTACTGCTTAACCAG & NM_013556 \\
\hline Gli1 & $5^{\prime}$ & MGH PrimerBank & CCAAGCCAACTTTATGTCAGGG & NM_010296 \\
\hline Gli1 & $3^{\prime}$ & MGH PrimerBank & AGCCCGCTTCTTTGTTAATTTGA & NM_010296 \\
\hline Ptch1 & $5^{\prime}$ & MGH PrimerBank & GCCTTCGCTGTGGGATTAAAG & NM_008957 \\
\hline Ptch1 & $3^{\prime}$ & MGH PrimerBank & CTTCTCCTATCTTCTGACGGGT & NM_008957 \\
\hline Wdpcp & $5^{\prime}$ & MGH PrimerBank & GCTTGACTGAACTACACCTGTG & NM_145425 \\
\hline Wdpcp & $3^{\prime}$ & MGH PrimerBank & TGAGTGTCCAAGGATAATCTCGT & NM_145425 \\
\hline Ccnd1 & $5^{\prime}$ & Lopez rios 2012 & CAGACGTTCAGAACCAGATTC & NM_007631 \\
\hline Cond1 & $3^{\prime}$ & Lopez rios 2012 & CCCTCCAATAGCAGCGAAAAC & NM_007631 \\
\hline Sdc3 & $5^{\prime}$ & MGH PrimerBank & AGAGGCCGGTGGATCTTGA & NM_011520 \\
\hline Sdc3 & $3^{\prime}$ & MGH PrimerBank & СTCCTGCTCGAAGTAGCCAGA & NM_011520 \\
\hline Cdh2 & $5^{\prime}$ & MGH PrimerBank & AGCGCAGTCTTACCGAAGG & NM_007664 \\
\hline Cdh2 & $3^{\prime}$ & MGH PrimerBank & TCGCTGCTITCATACTGAACTIT & NM_007664 \\
\hline Col2a1 & $5^{\prime}$ & MGH PrimerBank & GGGAATGTCCTCTGCGATGAC & NM_031163 \\
\hline Col2a1 & $3^{\prime}$ & MGH PrimerBank & GAAGGGGATCTCGGGGTTG & NM_031163 \\
\hline Sox9 & $5^{\prime}$ & MGH PrimerBank & AGTACCCGCATCTGCACAAC & NM_011448 \\
\hline Sox9 & $3^{\prime}$ & MGH PrimerBank & ACGAAGGGTCTCTTCTCGCT & NM_011448 \\
\hline Runx2 & $5^{\prime}$ & MGH PrimerBank & CCGCCTCAGTGATTTAGGGC & NM_009820 \\
\hline Runx2 & $3^{\prime}$ & MGH PrimerBank & GGGTCTGTAATCTGACTCTGTCC & NM_009820 \\
\hline Sp7 & $5^{\prime}$ & MGH PrimerBank & ATGGCGTCCTCTCTGCTTG & NM_130458 \\
\hline Sp7 & $3^{\prime}$ & MGH PrimerBank & TGAAAGGTCAGCGTATGGCTT & NM_130458 \\
\hline Bglap2 & $5^{\prime}$ & MGH PrimerBank & CTGACCTCACAGATCCCAAGC & NM_001032298 \\
\hline Bglap2 & $3^{\prime}$ & MGH PrimerBank & TGGTCTGATAGCTCGTCACAAG & NM_001032298 \\
\hline Colla1 & $5^{\prime}$ & MGH PrimerBank & TAAGGGTCCCCAATGGTGAGA & NM_007742 \\
\hline Colla1 & $3^{\prime}$ & MGH PrimerBank & GGGTCCCTCGACTCCTACAT & NM_007742 \\
\hline
\end{tabular}

composed of RNA isolated from 3 experimental replicates. All statistics were performed on difference from HPRT cycle counts to avoid error propagation.

\section{Western blotting}

The limb bud specific knockdown of Wdpcp was confirmed by individually genotyping embryos after forelimb buds had harvested for protein isolation. Forelimb bud protein content was isolated with Total Protein Extraction Kit (Millipore) supplemented with $5 \mathrm{mM}$ EDTA and 1X Halt Protease and Phosphatase Inhibitor Cocktail (Thermo Scientific). Samples were sonicated to homogenize lysate and protein concentration was quantified using BCA assay kit (Pierce) and standardized to same concentration using isolation buffer dilution. Western blots were performed as previously described [64]. Protein samples were subjected to reducing SDSPAGE and transferred to low-fluorescence background polyvinyl fluoride (PVDF) membranes (Millipore). Membranes were blocked in $3 \%$ milk in $0.25 \%$ Tween-20 in
TBS (TBS-T) for $1 \mathrm{~h}$ at room temperature and probed overnight at $4 \mathrm{C}$ with primary antibody in $1 \%$ milk/TBST. Primary antibodies used were goat anti-Wdpcp (1: 1000) (Santa Cruz, Sc-245,737 T-20) and mouse anti- $\beta$ actin (Santa Cruz sc-47,778) (1:1000). After washing with TBS-T, membranes were incubated for $1 \mathrm{~h}$ at room temperature with HRP conjugated anti-mouse (Abcam) (1:1000) or poly-HRP conjugated anti-goat antibody (Pierce) (1:2000) in $1 \%$ milk/TBS-T. Immunoreactive bands were visualized with SuperSignal West Dura Extended Duration Substrate (Thermo Scientific) on a Fotodyne imaging system. Each blot was repeated in duplicate, and representative blot is presented.

\section{Hedgehog responsiveness experiments}

Mesenchymal progenitor cells used in these experiments were isolated and expanded from E13.5 forelimbs. For all drug treatment experiments, cells were grown to confluence, trypsinized, and re-plated at full confluence $\left(150,000\right.$ cells $\left./ \mathrm{cm}^{2}\right)$ in appropriate size culture well in 
growth medium for 1 day before changing to starvation medium (DMEM supplemented with 0.25\% MSC qualified FBS). Previous studies had demonstrated that cell cycle arrest as induced by serum starvation and confluence is necessary to induce optimal ciliation and hedgehog responsiveness [65]. Following 2 days of culture with starvation medium, medium was changed to starvation medium supplemented with pharmacological agent dissolved in DMSO (Sigma) for 24h. RNA for RT-PCR and/or protein for Western Blots was isolated from cells at this time point. For expression studies, results presented are from 3 independent biological replicates. All drugs were diluted in dimethyl sulfoxide (DMSO) and added 1:1000 to culture medium. DMSO was added 1: 1000 for carrier control. The Click-iT Plus Edu 594 assay was used to quantify cell proliferation over final $24 \mathrm{~h}$ of cell culture. Following serum starvation period, $10 \mathrm{mM}$ EdU dissolved in PBS was added to culture medium at 1:1000 for a final concentration of $10 \mathrm{uM}$. Following fixation with $4 \%$ paraformaldehyde for $15 \mathrm{~min}$ at room temperature, EdU staining was performed per the manufacturer's protocol (Lifetechnologies). Hoechst staining was performed to identify all nuclei. Images were acquired on Zeiss inverted epifluorescent microscope with 10X objective. Three fields were captured for each treatment condition and presented images are representative. Three biologic replicates were performed per experimental condition.

\section{Micromass culture}

Forelimbs were obtained from $11.5 \mathrm{dpc}$ Prx1-cre; $W d p c p^{C y s 40 / F l o x}$ and control embryos. Micromass cultures were prepared as previously described [66-68]. Dissected limbs were dissociated in 1 unit/mL dispase (Stem Cell Technologies) for $1.5 \mathrm{~h}$ at $37^{\circ} \mathrm{C}$. Digested limbs were pipetted up and down with $200 \mathrm{uL}$ pipette to break up cells before being diluted in $10 \mathrm{~mL}$ 2:3 DMEM/ F-12 medium containing 10\% MSC qualified FBS (Invitrogen) to neutralize dispase. This suspension was passed through a 40 um filter and spun down to a pellet at $1200 \mathrm{~g}$. Cells were resuspended in 2:3 DMEM/F-12 medium and counted with hematocytometer. Cells were then divided into experimental groups, spun down and resuspended in 2:3 DMEM/F-12 medium supplemented with either DMSO or appropriate pharmacological agent dissolved in DMSO. Cells were diluted to 10 million cell/mL and spotted in $10 \mathrm{uL}$ droplets on Nunc 24-well culture dishes. Cells were allowed to adhere for $1.5 \mathrm{~h}$ in a cell incubator with humidified atmosphere containing $5 \% \mathrm{CO}_{2}$. After $2 \mathrm{~h}$, wells were flood with growth medium containing appropriate pharmacological agent. Cultures were harvested after 3 days. For Alcian Blue staining, cultures were fixed for $15 \mathrm{~min}$ at room temperature in $4 \%$ paraformaldehyde in $1 \mathrm{X}$ phosphate buffered saline before staining overnight at $4{ }^{\circ} \mathrm{C}$ with $1 \%$ Alcian Blue stain solution pH 1.0 (EK Industries). Stained cultures were washed $3 \mathrm{x}$ with phosphate buffered saline before imaging. Alcian Blue staining shows a representative image of 3 to 4 independent biological replicates [60].

\section{Histology and immunohistochemistry}

Specimens were fixed in $4 \%$ paraformaldehyde at indicated time point for $24 \mathrm{~h}$ overnight at $4 \mathrm{C}$ before being dehydrated and paraffin embedded. Forelimbs were sectioned at $7 \mu \mathrm{m}$ thickness. For Safranin O/Fast Green staining, sections were deparaffinized and rehydrated before being stained in Weigert's Iron Hematoxylin (Sigma) and 0.02\% aqueous Fast Green (Sigma) followed by a rinse in $1 \%$ acetic acid and $0.1 \%$ aqueous Safranin$\mathrm{O}$ (Sigma). For immunohistochemistry, ImmPRESS Excel amplified polymer staining kit (Vector Labs) was used [60]. Primary antibodies used for immunohistochemistry were rabbit anti-Osx/Sp7 (1:500) (Abcam, Ab22552), rabbit anti-Runx2 (1:500) (Santa Cruz, Sc-10, 758 M-70), and rabbit anti-Gli1 (Santa Cruz, Sc-20,687 H-300) (1:200). For immunocytochemistry, mesenchymal progenitors were plated on chamber slides and allowed to adhere for $24 \mathrm{~h}$. Cells were then fixed with $4 \%$ paraformaldehyde and stained with mouse antiacetylated alpha tubulin (1:200) (R\&D systems T7451 611B-1) overnight at $4 \mathrm{C}$ followed by chicken anti-mouse Alexafluor 647 (1:200) (Invitrogen) and DAPI counterstain.

\section{Mesenchymal progenitor isolation}

Mesenchymal progenitor cells were isolated from the limbs of E13.5 embryos that were digested in 0.5\% Trypsin EDTA and mechanically disrupted. Trypsin was neutralized after $5 \mathrm{~min}$ at $37 \mathrm{C}$ with DMEM supplemented with 10\% MSC qualified FBS (Gibco) with 1X Penicillin/ Streptomycin/Fungizone (Gibco) growth medium. Cells were pipetted up and down to break up remaining tissue before spinning at $1000 \mathrm{~g}$ to pellet in $15 \mathrm{~mL}$ Vulcan tube. Cells were then resuspended in growth medium and plated on T75 at what was considered passage 0. Cells were expanded 2 days with growth medium changed each day. Cells were passaged on day 2 and split (1:4). Cells were grown to $90 \%$ confluence, passaged, and frozen in cryoprotective freezing medium (Lonza) for storage in liquid nitrogen. All experiments using were conducted at passage 3 or 4 [60].

\section{Osteogenic differentiation assays}

Following expansion, mesenchymal progenitor cells were seeded at $70 \%$ confluence $\left(100,000\right.$ cells $\left./ \mathrm{cm}^{2}\right)$ in growth medium for 2 days before changing to standard osteogenic medium containing $1 \mathrm{mM} \beta$-glycerolphosphate, $100 \mathrm{nM}$ 
ascorbic acid, and $20 \mathrm{ng} / \mathrm{mL}$ rBMP2 (Peprotech) supplemented with $10 \mathrm{nM}$ smooth agonist (SAG, Calbiochem) similar to prior studies $[10,53]$. Osteogenic medium was changed every 4 days. Alkaline phosphatase activity was measured with paranitrophenyl phosphate assay (Sigma) at day 4 of osteogenic differentiation. Eight independent biological replicates were used for quantification. Alizarin red staining was used to assay calcium matrix deposition of osteogenic cultures. Cells were fixed in $70 \%$ ethanol before being stained for $15 \mathrm{~min}$ with $2 \%$ alizarin red solution at $\mathrm{pH} 4.2$ (Rowley Biochemical Institute). For quantification, $1 \mathrm{~mL}$ of cetylpyridinium chloride was used per 6 well plate well to solubilize dye. DNA was isolated from an analogous 6 well plate well with $1 \mathrm{~mL}$ of $0.5 \%$ Triton X100 in distilled water and quantified using Quant-iT PicoGreen dsDNA Assay Kit (Life Technologies). Soluble alizarin red was quantified spectroscopically $\left(\mathrm{A}_{580}\right)$ [60]. Six independent biologic replicates were used for quantification.

\section{Supplementary Information}

The online version contains supplementary material available at https://doi. org/10.1186/s12861-021-00241-9.

\section{Additional file 1: Figure S1. Genotyping of $\mathrm{Wdpcp}^{\mathrm{Cys} 40}, \mathrm{Wdpcp}{ }^{\mathrm{Flox}}$,}

and Prx1-cre mice. The Cys40 allele is a result of an A- $>\mathrm{G}$ base change at the end of exon 5 that causes a splice defect with exon 5 excluded from the mRNA. This splice defect results in a premature stop codon (Cui et al. 2013). This allele is genotyped by Sanger sequencing (A). The construct for the inducible Wdpcp deletion had a PGKNeo cassette flanked by FRT sites that was removed via breeding to a mouse with constitutive expression of the FLP recombinase. The conditional mouse model used in this study carries two LoxP sites on either side of exon 5 (Cui et al. 2013). Cre mediated recombination results in deletion of exon 5 , forming a functional null that mimics the Cys40 mutant. Mice carrying the Prx1-cre allele were identified by PCR amplification of a region of the Cre recombinase cDNA (B) that resulted in a $102 \mathrm{bp}$ product (C). Mice carrying the floxed allele of $W d p c p$ were identified with primers that amplified a fragment containing (424 bp) or lacking (262 bp) the inserted LoxP site (C). Figure S2. Defective ciliogenesis in Wdpcp-cKO mesenchymal progenitor cells. Mesenchymal progenitors from control and Wdpcp-cKO mice were stained for acetylated alpha tubulin (red), a marker of primary cilia (white arrows). Acetylated alpha tubulin is a modified form of alpha tubulin found in high concentrations within primary cilia. Nuclei were stained with DAPI (blue) for counterstain.

\section{Acknowledgements}

The authors thank other members of the Center for Cellular and Molecular Engineering at the University of Pittsburgh, especially Dr. Thomas Lozito, for their helpful suggestions and assistance with technical protocols. Authors would like to thank the University of Pittsburgh Genomics Core Laboratory for their help with genotyping.

\section{Authors' contributions}

$\mathrm{ML}$ and JG performed all cell experiments and histology. ML, YT, and BW performed mouse husbandry, breeding, and genotyping. RT, PA and ML conceived work and designed studies. All authors read and approved the final manuscript.

\section{Funding}

This work was supported by NHLBI training grant to MTL (T32 HL076124-08), the Pennsylvania State Tobacco Fund, and the Pittsburgh Foundation.

\section{Availability of data and materials}

All data generated or analysed during this study are included in this published article.

\section{Declarations}

\section{Ethics approval and consent to participate}

All animal experimentation was approved by and carried out in accordance with the Animal Care and Use Committee of University of Pittsburgh School of Medicine. All experiments were performed in accordance with relevant guidelines and regulations.

\section{Consent for publication}

Not applicable.

\section{Competing interests}

The authors declare that they have no competing interests.

Received: 7 January 2021 Accepted: 7 April 2021

Published online: 05 July 2021

\section{References}

1. Goetz SC, Anderson KV. The primary cilium: a signalling Centre during vertebrate development. Nat Rev Genet. 2010;11(5):331-44. https://doi.org/1 $0.1038 /$ nrg 2774

2. Ishikawa $H$, Marshall WF. Ciliogenesis: building the cell's antenna. Nat Rev Mol Cell Biol. 2011;12(4):222-34. https://doi.org/10.1038/nrm3085.

3. Braun DA, Hildebrandt F. Ciliopathies. Cold Spring Harb Perspect Biol. 2017; 9:3.

4. Toriyama M, Lee C, Taylor SP, Duran I, Cohn DH, Bruel AL, et al. The ciliopathy-associated CPLANE proteins direct basal body recruitment of intraflagellar transport machinery. Nat Genet. 2016;48(6):648-56. https://doi. org/10.1038/ng.3558.

5. Aguilar A. Ciliopathies: CPLANE regulates intraflagellar transport. Nat Rev Nephrol. 2016:12(7):376. https://doi.org/10.1038/nrneph.2016.74.

6. Song B, Haycraft CJ, Seo HS, Yoder BK, Serra R. Development of the postnatal growth plate requires intraflagellar transport proteins. Dev Biol. 2007; 305(1):202-16. https://doi.org/10.1016/j.ydbio.2007.02.003.

7. McGlashan SR, Haycraft CJ, Jensen CG, Yoder BK, Poole CA. Articular cartilage and growth plate defects are associated with chondrocyte cytoskeletal abnormalities in Tg737orpk mice lacking the primary cilia protein polaris. Matrix Biol. 2007;26(4):234-46. https://doi.org/10.1016/j.ma tbio.2006.12.003

8. Wang C, Yuan X, Yang S. IFT80 is essential for chondrocyte differentiation by regulating hedgehog and Wnt signaling pathways. Exp Cell Res. 2013; 319(5):623-32. https://doi.org/10.1016/j.yexcr.2012.12.028.

9. Yuan X, Yang S. Deletion of IFT80 impairs epiphyseal and articular cartilage formation due to disruption of chondrocyte differentiation. PLoS One. 2015: 10(6):e0130618. https://doi.org/10.1371/journal.pone.0130618.

10. Yang $S$, Wang $C$. The intraflagellar transport protein IFT80 is required for cilia formation and osteogenesis. Bone. 2012;51(3):407-17. https://doi.org/1 0.1016/j.bone.2012.06.021.

11. Yuan X, Cao J, He X, Serra R, Qu J, Cao X, et al. Ciliary IFT80 balances canonical versus non-canonical hedgehog signalling for osteoblast differentiation. Nat Commun. 2016;7(1):11024. https://doi.org/10.1038/ ncomms 11024.

12. Haycraft CJ, Zhang Q, Song B, Jackson WS, Detloff PJ, Serra R, et al. Intraflagellar transport is essential for endochondral bone formation. Development. 2007:134(2):307-16. https://doi.org/10.1242/dev.02732.

13. Chang CF, Serra R. Ift88 regulates hedgehog signaling, Sfrp5 expression, and beta-catenin activity in post-natal growth plate. J Orthop Res. 2013;31(3): 350-6. https://doi.org/10.1002/jor.22237.

14. Irianto J, Ramaswamy G, Serra R, Knight MM. Depletion of chondrocyte primary cilia reduces the compressive modulus of articular cartilage. J Biomech. 2014;47(2):579-82. https://doi.org/10.1016/j.jbiomech.2013.11.040.

15. Moore ER, Yang $Y$, Jacobs CR. Primary cilia are necessary for Prx1-expressing cells to contribute to postnatal skeletogenesis. J Cell Sci. 2018;131:16.

16. Moore ER, Zhu YX, Ryu HS, Jacobs CR. Periosteal progenitors contribute to load-induced bone formation in adult mice and require primary cilia to sense mechanical stimulation. Stem Cell Res Ther. 2018;9(1):190. https://doi. org/10.1186/s13287-018-0930-1 
17. Cui C, Chatterjee B, Lozito TP, Zhang Z, Francis RJ, Yagi H, et al. Wdpcp, a $P C P$ protein required for ciliogenesis, regulates directional cell migration and cell polarity by direct modulation of the actin cytoskeleton. PLoS Biol. 2013;11(11):e1001720. https://doi.org/10.1371/journal.pbio.1001720.

18. Heydeck W, Zeng H, Liu A. Planar cell polarity effector gene fuzzy regulates cilia formation and hedgehog signal transduction in mouse. Dev Dyn. 2009; 238(12):3035-42. https://doi.org/10.1002/dvdy.22130.

19. Zeng $H$, Hoover AN, Liu A. PCP effector gene Inturned is an important regulator of cilia formation and embryonic development in mammals. Dev Biol. 2010;339(2):418-28. https://doi.org/10.1016/j.ydbio.2010.01.003.

20. Chang R, Petersen JR, Niswander LA, Liu A. A hypomorphic allele reveals an important role of inturned in mouse skeletal development. Dev Dyn. 2015; 244(6):736-47. https://doi.org/10.1002/dvdy.24272.

21. Collier S, Lee $H$, Burgess R, Adler P. The WD40 repeat protein fritz links cytoskeletal planar polarity to frizzled subcellular localization in the Drosophila epidermis. Genetics. 2005;169(4):2035-45. https://doi.org/10.1 534/genetics.104.033381

22. Kim SK, Shindo A, Park TJ, Oh EC, Ghosh S, Gray RS, et al. Planar cell polarity acts through septins to control collective cell movement and ciliogenesis. Science. 2010;329(5997):1337-40. https://doi.org/10.1126/science.1191184.

23. Forsythe E, Beales PL. Bardet-Biedl syndrome. Eur J Human Gen. 2013;21(1): 8-13. https://doi.org/10.1038/ejhg.2012.115.

24. Ashe A, Butterfield NC, Town L, Courtney AD, Cooper AN, Ferguson C, et al. Mutations in mouse Ift144 model the craniofacial, limb and rib defects in skeletal ciliopathies. Hum Mol Genet. 2012;21(8):1808-23. https://doi.org/1 0.1093/hmg/ddr613.

25. Bimonte S, De Angelis A, Quagliata L, Giusti F, Tammaro R, Dallai R, et al. Ofd1 is required in limb bud patterning and endochondral bone development. Dev Biol. 2011;349(2):179-91. https://doi.org/10.1016/j.ydbio.2010.09.020.

26. Ruiz-Perez VL, Blair HJ, Rodriguez-Andres ME, Blanco MJ, Wilson A, Liu YN, et al. Evc is a positive mediator of Ihh-regulated bone growth that localises at the base of chondrocyte cilia. Development. 2007;134(16):2903-12. https://doi.org/10.1242/dev.007542.

27. Logan M, Martin JF, Nagy A, Lobe C, Olson EN, Tabin CJ. Expression of Cre recombinase in the developing mouse limb bud driven by a Prxl enhancer. Genesis. 2002;33(2):77-80. https://doi.org/10.1002/gene.10092.

28. Long F. Building strong bones: molecular regulation of the osteoblast lineage. Nat Rev Mol Cell Biol. 2011;13(1):27-38. https://doi.org/10.1038/ nrm3254.

29. Haraguchi R, Kitazawa R, Kohara Y, Ikedo A, Imai Y, Kitazawa S. Recent Insights into Long Bone Development: Central Role of Hedgehog Signaling Pathway in Regulating Growth Plate. Int J Mol Sci. 2019;20:23.

30. Dai P, Akimaru H, Tanaka Y, Maekawa T, Nakafuku M, Ishii S. Sonic hedgehog-induced activation of the Gli1 promoter is mediated by GLI3. J Biol Chem. 1999;274(12):8143-52. https://doi.org/10.1074/jbc.274.12.8143.

31. Zhulyn O, Li D, Deimling S, Vakili NA, Mo R, Puviindran V, et al. A switch from low to high Shh activity regulates establishment of limb progenitors and signaling centers. Dev Cell. 2014;29(2):241-9. https://doi.org/10.1016/j. devcel.2014.03.002

32. Briscoe J, Therond PP. The mechanisms of hedgehog signalling and its roles in development and disease. Nat Rev Mol Cell Biol. 2013;14(7):416-29. https://doi.org/10.1038/nrm3598.

33. St-Jacques B, Hammerschmidt M, McMahon AP. Indian hedgehog signaling regulates proliferation and differentiation of chondrocytes and is essential for bone formation. Genes Dev. 1999;13(16):2072-86. https://doi.org/10.11 01/gad.13.16.2072

34. Dexheimer $\mathrm{V}$, Frank S, Richter W. Proliferation as a requirement for in vitro chondrogenesis of human mesenchymal stem cells. Stem Cells Dev. 2012; 21(12):2160-9. https://doi.org/10.1089/scd.2011.0670.

35. Fischer J, Knoch N, Sims T, Rosshirt N, Richter W. Time-dependent contribution of BMP, FGF, IGF, and $\mathrm{HH}$ signaling to the proliferation of mesenchymal stroma cells during chondrogenesis. J Cell Physiol. 2018; 233(11):8962-70. https://doi.org/10.1002/jcp.26832.

36. Lopez-Rios J, Speziale D, Robay D, Scotti M, Osterwalder M, Nusspaumer G, et al. GLI3 constrains digit number by controlling both progenitor proliferation and BMP-dependent exit to chondrogenesis. Dev Cell. 2012; 22(4):837-48. https://doi.org/10.1016/j.devcel.2012.01.006.

37. Bhumiratana $S$, Eton $R E$, Oungoulian $S R$, Wan LQ, Ateshian GA, VunjakNovakovic G. Large, stratified, and mechanically functional human cartilage grown in vitro by mesenchymal condensation. Proc Natl Acad Sci U S A. 2014;111(19):6940-5. https://doi.org/10.1073/pnas.1324050111.
38. Gegg C, Yang F. The effects of ROCK inhibition on mesenchymal stem cell Chondrogenesis are culture model dependent. Tissue Eng Part A. 2020; 26(3-4):130-9. https://doi.org/10.1089/ten.tea.2019.0068.

39. Komori T, Yagi H, Nomura S, Yamaguchi A, Sasaki K, Deguchi K, et al. Targeted disruption of Cbfa1 results in a complete lack of bone formation owing to maturational arrest of osteoblasts. Cell. 1997;89(5):755-64. https:// doi.org/10.1016/S0092-8674(00)80258-5.

40. Nakashima K, Zhou X, Kunkel G, Zhang Z, Deng JM, Behringer RR, et al. The novel zinc finger-containing transcription factor osterix is required for osteoblast differentiation and bone formation. Cell. 2002;108(1):17-29. https://doi.org/10.1016/S0092-8674(01)00622-5.

41. Geister KA, Brinkmeier ML, Cheung LY, Wendt J, Oatley MJ, Burgess DL, et al. LINE-1 mediated insertion into Pocla (protein of centriole 1 a) causes growth insufficiency and male infertility in mice. PLoS Genet. 2015;11(10): e1005569. https://doi.org/10.1371/journal.pgen.1005569.

42. Paige Taylor S, Kunova Bosakova M, Varecha M, Balek L, Barta T, Trantirek L, et al. An inactivating mutation in intestinal cell kinase, ICK, impairs hedgehog signalling and causes short rib-polydactyly syndrome. Hum Mol Genet. 2016;25(18):3998-4011. https://doi.org/10.1093/hmg/ddw240.

43. Yin Y, Bangs F, Paton IR, Prescott A, James J, Davey MG, et al. The Talpid3 gene (KIAA0586) encodes a centrosomal protein that is essential for primary cilia formation. Development. 2009;136(4):655-64. https://doi.org/10.1242/ dev.028464.

44. Bangs F, Antonio N, Thongnuek P, Welten M, Davey MG, Briscoe J, et al. Generation of mice with functional inactivation of talpid3, a gene first identified in chicken. Development. 2011;138(15):3261-72. https:/doi.org/10.1242/dev.063602.

45. Caparros-Martin JA, Valencia M, Reytor E, Pacheco M, Fernandez M, PerezAytes A, et al. The ciliary Evc/Evc2 complex interacts with Smo and controls hedgehog pathway activity in chondrocytes by regulating Sufu/Gli3 dissociation and Gli3 trafficking in primary cilia. Hum Mol Genet. 2013;22(1): 124-39. https://doi.org/10.1093/hmg/dds409.

46. Howard PW, Howard TL, Maurer RA. Generation of mice with a conditional allele for Ift172. Transgenic Res. 2010;19(1):121-6. https://doi.org/10.1007/ s11248-009-9292-X.

47. Kolpakova-Hart E, Jinnin M, Hou B, Fukai N, Olsen BR. Kinesin-2 controls development and patterning of the vertebrate skeleton by hedgehog-and Gli3-dependent mechanisms. Dev Biol. 2007;309(2):273-84. https://doi.org/1 0.1016/j.ydbio.2007.07.018.

48. Huangfu D, Anderson KV. Cilia and hedgehog responsiveness in the mouse. Proc Natl Acad Sci U S A. 2005;102(32):11325-30. https://doi.org/10.1073/ pnas.0505328102

49. Qin J, Lin Y, Norman RX, Ko HW, Eggenschwiler JT. Intraflagellar transport protein 122 antagonizes sonic hedgehog signaling and controls ciliary localization of pathway components. Proc Natl Acad Sci U S A. 2011;108(4): 1456-61. https://doi.org/10.1073/pnas.1011410108.

50. Li J, Wang C, Wu C, Cao T, Xu G, Meng Q, et al. PKA-mediated Gli2 and Gli3 phosphorylation is inhibited by hedgehog signaling in cilia and reduced in Talpid3 mutant. Dev Biol. 2017;429(1):147-57. https://doi.org/10.1016/j. ydbio.2017.06.035

51. Deng A, Zhang H, Hu M, Liu S, Gao Q, Wang Y, et al. Knockdown of Indian hedgehog protein induces an inhibition of cell growth and differentiation in osteoblast MC3T3E1 cells. Mol Med Rep. 2017;16(6):7987-92. https://doi. org/10.3892/mmr.2017.7669.

52. Deng Q, Li P, Che M, Liu J, Biswas S, Ma G, et al. Activation of hedgehog signaling in mesenchymal stem cells induces cartilage and bone tumor formation via Wnt/beta-catenin. Elife. 2019;8:1. https://doi.org/10.7554/eLife.50208.

53. Tummala $P$, Arnsdorf EJ, Jacobs CR. The role of primary cilia in mesenchymal stem cell differentiation: a pivotal switch in guiding lineage commitment. Cell Mol Bioeng. 2010;3(3):207-12. https://doi.org/10.1007/ s12195-010-0127-x.

54. Gao B, Song H, Bishop K, Elliot G, Garrett L, English MA, et al. Wnt signaling gradients establish planar cell polarity by inducing Vangl2 phosphorylation through Ror2. Dev Cell. 2011;20(2):163-76. https://doi.org/10.1016/j.devcel.2 011.01.001.

55. Kuss P, Kraft K, Stumm J, Ibrahim D, Vallecillo-Garcia P, Mundlos S, et al. Regulation of cell polarity in the cartilage growth plate and perichondrium of metacarpal elements by HOXD13 and WNT5A. Dev Biol. 2014;385(1):8393. https://doi.org/10.1016/j.ydbio.2013.10.013.

56. Randall RM, Shao YY, Wang L, Ballock RT. Activation of Wht planar cell polarity (PCP) signaling promotes growth plate column formation in vitro. J Orthop Res. 2012;30(12):1906-14. https://doi.org/10.1002/jor.22152. 
57. Ocbina PJ, Tuson M, Anderson KV. Primary cilia are not required for norma canonical Wnt signaling in the mouse embryo. PLoS One. 2009;4(8):e6839. https://doi.org/10.1371/journal.pone.0006839.

58. Gibbs BC, Damerla RR, Vladar EK, Chatterjee B, Wan Y, Liu X, et al. Prickle1 mutation causes planar cell polarity and directional cell migration defects associated with cardiac outflow tract anomalies and other structural birth defects. Biol Open. 2016;5(3):323-35. https://doi.org/10.1242/bio.015750.

59. Liu C, Lin C, Gao C, May-Simera H, Swaroop A, Li T. Null and hypomorph Prickle1 alleles in mice phenocopy human Robinow syndrome and disrupt signaling downstream of Wnt5a. Biol Open. 2014;3(9):861-70. https://doi. org/10.1242/bio.20148375.

60. Langhans MT. Wdpcp affects skeletogenesis via the hedgehog pathway: University of Pittsburgh; 2015

61. Mis EK, Liem KF Jr, Kong Y, Schwartz NB, Domowicz M, Weatherbee SD. Forward genetics defines Xylt1 as a key, conserved regulator of early chondrocyte maturation and skeletal length. Dev Biol. 2014;385(1):67-82. https://doi.org/10.1016/j.ydbio.2013.10.014

62. de Kok JB, Roelofs RW, Giesendorf BA, Pennings JL, Waas ET, Feuth T, et al. Normalization of gene expression measurements in tumor tissues: comparison of 13 endogenous control genes. Lab Investig. 2005;85(1):1549.

63. Zhai Z, Yao Y, Wang Y. Importance of suitable reference gene selection for quantitative RT-PCR during ATDC5 cells chondrocyte differentiation. PLoS One. 2013:8(5):e64786. https://doi.org/10.1371/journal.pone.0064786.

64. Lozito TP, Tuan RS. Mesenchymal stem cells inhibit both endogenous and exogenous MMPs via secreted TIMPs. J Cell Physiol. 2011;226(2):385-96. https://doi.org/10.1002/jcp.22344.

65. Rohatgi R, Milenkovic L, Scott MP. Patched1 regulates hedgehog signaling at the primary cilium. Science. 2007;317(5836):372-6. https://doi.org/10.112 6/science.1139740

66. Bruce SJ, Butterfield NC, Metzis V, Town L, McGlinn E, Wicking C. Inactivation of Patched 1 in the mouse limb has novel inhibitory effects on the chondrogenic program. J Biol Chem. 2010;285(36):27967-81. https://doi. org/10.1074/jbc.M109.091785

67. Denker AE, Haas AR, Nicoll SB, Tuan RS. Chondrogenic differentiation of murine $\mathrm{C} 3 \mathrm{H} 10 \mathrm{~T} 1 / 2$ multipotential mesenchymal cells: I. stimulation by bone morphogenetic protein-2 in high-density micromass cultures. Differentiation. 1999;64(2):67-76. https://doi.org/10.1046/j.1432-0436.1999. 6420067.x.

68. DeLise AM, Stringa E, Woodward WA, Mello MA, Tuan RS. Embryonic limb mesenchyme micromass culture as an in vitro model for chondrogenesis and cartilage maturation. Methods Mol Biol. 2000;137:359-75. https://doi. org/10.1385/1-59259-066-7:359

\section{Publisher's Note}

Springer Nature remains neutral with regard to jurisdictional claims in published maps and institutional affiliations.

Ready to submit your research? Choose BMC and benefit from:

- fast, convenient online submission

- thorough peer review by experienced researchers in your field

- rapid publication on acceptance

- support for research data, including large and complex data types

- gold Open Access which fosters wider collaboration and increased citations

- maximum visibility for your research: over $100 \mathrm{M}$ website views per year

At $\mathrm{BMC}$, research is always in progress.

Learn more biomedcentral.com/submissions 